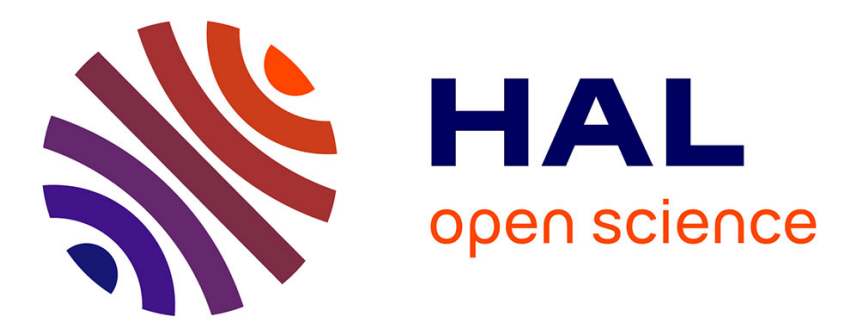

\title{
Additive Manufacturing: Current Status and Future Prospects
}

Jyotirmoyee Bhattacharjya, Sonali Tripathi, Andrew Taylor, Margaret Taylor, David Walters

\section{- To cite this version:}

Jyotirmoyee Bhattacharjya, Sonali Tripathi, Andrew Taylor, Margaret Taylor, David Walters. Additive Manufacturing: Current Status and Future Prospects. 15th Working Conference on Virtual Enterprises (PROVE), Oct 2014, Amsterdam, Netherlands. pp.365-372, 10.1007/978-3-662-447451_36. hal-01392138

\section{HAL Id: hal-01392138 \\ https://hal.inria.fr/hal-01392138}

Submitted on 4 Nov 2016

HAL is a multi-disciplinary open access archive for the deposit and dissemination of scientific research documents, whether they are published or not. The documents may come from teaching and research institutions in France or abroad, or from public or private research centers.
L'archive ouverte pluridisciplinaire HAL, est destinée au dépôt et à la diffusion de documents scientifiques de niveau recherche, publiés ou non, émanant des établissements d'enseignement et de recherche français ou étrangers, des laboratoires publics ou privés. 


\title{
Additive Manufacturing: Current Status and Future Prospects
}

\author{
Jyotirmoyee Bhattacharjya ${ }^{1}$, Sonali Tripathi ${ }^{1}$, Andrew Taylor ${ }^{2}$, \\ Margaret Taylor ${ }^{2}$ and David Walters ${ }^{1}$ \\ ${ }^{1}$ Institute of Transport and Logistics Studies, The University of Sydney, NSW 2006, \\ Australia \\ ${ }^{2}$ Bradford University School of Management, Emm Lane, Bradford, West Yorkshire, BD9 \\ $4 \mathrm{JL}, \mathrm{UK}$ \\ \{jyotirmoyee.bhattacharjya, sonali.tripathi, david.walters\}@sydney.edu.au \\ $\{$ w.a.taylor, m.taylor4\}@bradford.ac.uk
}

\begin{abstract}
The potential implications of additive manufacturing or 3D printing technology are being recognized across a number of different industries. In developed countries where the traditional manufacturing sector has experienced decline, the developments in additive manufacturing present potential opportunities for growth. The paper presents the outcomes of preliminary data analysis from an exploratory survey of senior managers working in the additive manufacturing sector in the Australasian region. The analysis suggests that while there has been progress, there is scope for improving technologies and reducing costs in order to facilitate wider adoption of and greater business value from 3D printing.
\end{abstract}

Keywords: additive manufacturing, 3D printing, business model, sustainability.

\section{Background}

In an environment of increasing competition from developing countries, manufacturers in western countries are increasingly focusing on high-end products or unique production processes or environmentally sustainable product lines [1]. There is growing interest in applications of innovative manufacturing technologies across a number of sectors. This paper focuses on one type of advanced manufacturing practice - additive manufacturing or $3 \mathrm{D}$ printing and presents preliminary findings from a survey conducted in the Australasian region.

\subsection{Trends in Additive Manufacturing}

Three-dimensional (3D) printing is an example of additive manufacturing that is becoming increasingly popular [5][6]. In 2012, the global market for additive manufacturing products and services grew to over USD 2 billion and the unit sales of industrial systems reached around 8000 units. A recent report from the UK [2] 
suggests that although additive manufacturing provides an attractive option for organizations seeking to continue to be competitive in manufacturing, the technology currently has less than $8 \%$ market penetration. While this is due to a combination of lack of greater awareness within the global manufacturing community and shortcomings of existing technology, there is a great scope for future growth in this area.

Three key industries, automotive, aerospace and medical, have adopted and seen developments in additive manufacturing technology for various reasons [7]. The automotive sector has used the technology to get new products to market quickly and in a cost effective manner, thereby achieving savings in the overall development of vehicles. The aerospace sector has adopted the technology for its ability to produce very complex, high performance products especially in the context of carbon composite aircraft designs. The ease of converting 3D medical imaging data has made additive manufacturing attractive to the medical industry. However, speed, accuracy, nonlinearity, material properties and system costs remain as limitations of the technology. There are currently several $3 \mathrm{D}$ printing machines available to potential and existing commercial users. These printers can work with various materials to produce parts that can be used in rapid prototyping applications [8].

An overwhelming attraction of additive manufacturing is its ability to meet customer requirements for product customization and product immediacy [3]. However, while the rapidly developing technology is well documented, the business implications for manufacturing organizations adopting/using additive manufacturing appears to have received limited attention in the academic literature. This paper aims to address this gap in the literature in the Australasian context.

\section{Research Method and Data Collection}

This paper reports on the Australian data from an exploratory survey of users of additive manufacturing conducted in Europe, North America and Australasia by a collaborating team of researchers in the Australasia and the UK. The Australasian users of additive manufacturing (organizations and key contact points) were identified with the help of the Advanced Manufacturing Cooperative Research Centre in Australia. Of the 42 users invited to participate in the study, 17 responded but 13 (31\%) actually completed the online survey. The online survey contains both Likert scale questions as well open-ended questions allowing users to describe their experiences with additive manufacturing and their understanding of the current and future of uses of the technology. Although the response rate in Australasia was considerably lower than that in Europe/North America, the data provided useful insights for future in-depth case study based research. The users represented various sectors including consumer durables and disposables, industrial components and products as well as consultancy services (indirect users); ten of the 13 respondents held senior management roles. Most of the organizations $(61.5 \%)$ have been involved in additive manufacturing for less than five years. Others $(23.1 \%)$ had been working in the area for five to 10 years or 10 to 15 years $(15.4 \%)$. A majority of the manufacturing firms were found to be using non-metals in their production processes. 
The proportion of respondents involved in different types of additive manufacturing applications is shown in Table 1 below.

Table 1. Respondent involvement in additive manufacturing applications

\begin{tabular}{lc}
\hline Additive manufacturing applications & $\begin{array}{c}\text { of } \\
\text { Respondents }\end{array}$ \\
\hline Rapid prototyping for new product development & 69.2 \\
Rapid manufacturing (complete products) & 7.7 \\
Rapid manufacturing (product components that subsequently become & 38.5 \\
part of a complete product) & 7.7 \\
Other & \\
\hline
\end{tabular}

\section{Findings}

\subsection{Current Status of Additive Manufacturing}

A number of potential benefits of additive manufacturing have been noted in the press and the academic literature. In this study, a high proportion of respondents (77\%) strongly agreed that the reduced time lag between design and production was a benefit of this type of manufacturing. This is aligned with common assertions in the press in relation to this technology. The top three benefits identified by respondents are shown in Figure 1 below. 


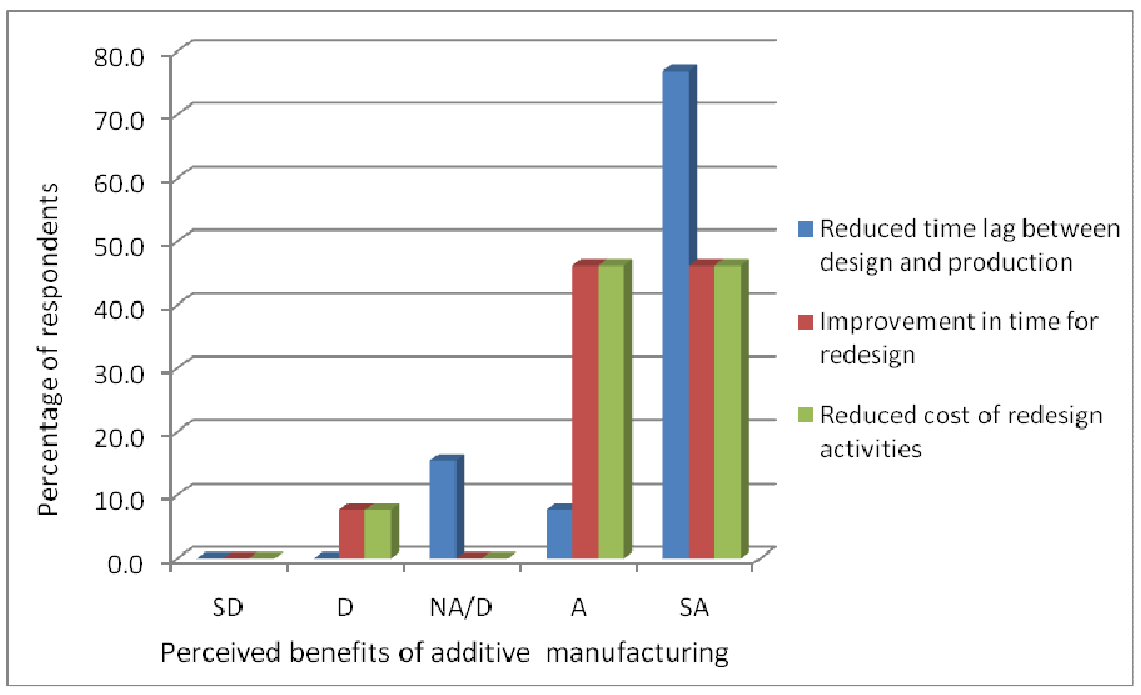

Fig. 1. Benefits of additive manufacturing based on the experiences of respondents $(S D=$ strongly disagree, $\mathrm{D}=$ disagree, $\mathrm{NA} / \mathrm{D}=$ neither agree nor disagree, $\mathrm{A}=$ agree, $\mathrm{SA}=$ strongly disagree)

When describing their experiences with output quality from additive manufacturing, majority of the respondents $(69 \%)$ were positive while noting issues with materials, machines/platforms and outputs. One respondent made the following observation on platform and material issues while noting the quick turnaround time: "We have just completed an extremely busy two months. There is no way we could have met demand with out our additive manufacturing system. Consistency is dependent on understanding the accurate areas on the printing platform. Printing the same file on different areas of the platform will result in dimension differences. The surface finish is consistently better than hand made prosthetics, in the majority of parts. The part material we use is an acrylic. It is a little brittle." Another respondent noted the process improvements that had occured over time while observing that the technology had a long way to go: "We have been using additive manufacturing for 15 years in a prototyping function. The quality of the processes is improving in our experience and we can prototype parts which appear very close to the production equivalent. However we are yet to see an additive process that can replace traditional production processes in terms of physical material properties - strength, durability, stability. This is especially true for processes which involve work hardening or internal stress loading".

The adoption of additive manufacturing has impacts on a business through the requirement for additional resources and staffing/training as well as value creation through improved turnaround times and positive changes in business-to-business interactions. One respondent from heathcare manufacturing provided the following insights: "Two thirds of our production line required retraining. Interest in our business increased, so the profile of our business attracted more attention from our 
current customers, new customers and competitors. Subsequently this opened new revenue sources. We are subcontracting to new clients who were previously competitors. We are building a network of Dental laboratories in Australia and New Zealand that we will be training to utilize additive manufacturing in their businesses. Our business has now international markets, where previously our market was restricted to domestic Dental Laboratories." Another senior respondent from the automotive sector noted: "Additional facilities and staff added, increase in products developed with reduced turnaround times. Quality of our tool makers has increased dramatically; now 3D assembled parts can be sent to them before tooling starts as it allows them to visualize parts we are developing as a whole, this helps deliver a better quality part as well as speeds up tooling process. Rapid prototyping is now one of the company's biggest marketing assets with every potential customer being given a site visit and being shown the prototype machines' potential."

\subsection{Future of Additive Manufacturing}

When asked to identify the usefulness of potential developments in additive manufacturing equipment/materials, a high proportion of respondents (75\%) strongly agreed that further decreases in printer cost would be useful to them. The top four useful potential developments identified by respondents are shown in Figure 2 below.

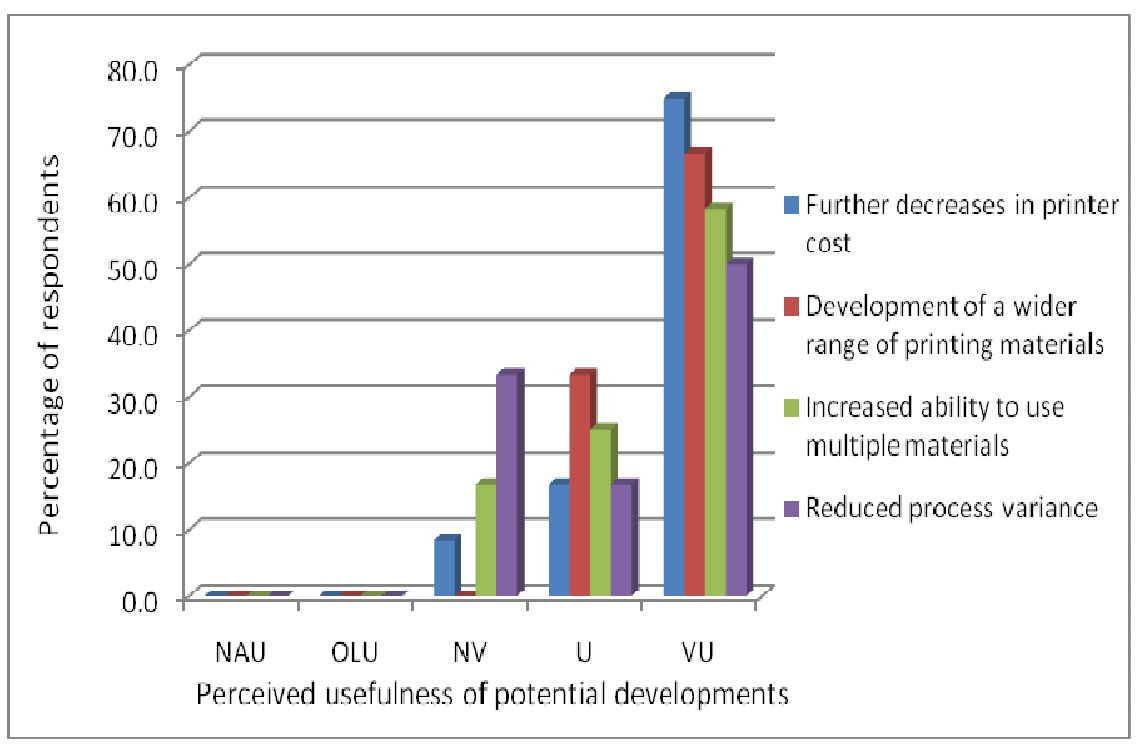

Fig. 2. Usefulness of potential developments in additive manufacturing equipment/materials (NAU=not at all useful, OLU=of limited use, $N V=$ neutral view, $U=$ useful, VU=very useful) 
Additive manufacturing was viewed to be an environmentally sustainable approach by $77 \%$ percent of the respondents. Respondents identified reduction in material wastage and energy usage as key reasons why this approach to manufacturing was a greener solution. Reduction in transportation related energy usage by manufacturing at the point of use was also noted.

Respondents were divided as to the potential for additive manufacturing to increase on-shoring/re-shoring of manufacturing actives in the near future. Around $46 \%$ of respondents believed that additive manufacturing creates opportunities for local suppliers. While noting volume limitations, one respondent reported positive changes in their own practices: "Unless the quality of finished parts improves for volume manufacturing we will continue to largely use the technology for prototyping....having said that we are now getting prototype parts done locally where they were regularly manufactured offshore so a net benefit." However, the developments in additive manufacturing in China (e.g., [4]) have led to counterarguments from other respondents: "We find that for our purposes this is not a consideration. Rapid prototyping is based on speed of TAT [turnaround time] and quality of the result. We regularly use Chinese manufacturers for this."

Most respondents (77\%) agreed that given President Obama's announcement of funding for a National Additive Manufacturing Innovation Institute (America Makes) in 2012, other governments should invest in more additive manufacturing research activity. Reflecting on the Australian context, one respondent made the following observation: "To become competitive and stay competitive in the changing world, we must be leaders in technology. There is still so much to learn and so much to be gained by becoming a global leader in additive manufacturing. It is unfortunate Australia has missed the boat in the early years of Additive Manufacturing technology. But there is still much to be learned, I have many questions that cannot be answered. I have much to learn. How will I continue to develop my underpinning knowledge with no resource tools? Additive Manufacturing is the future. If we want to be a part of the future we must invest in the future." However, others raised issues such as the consequences of too great a concentration of funding on one type of technology at the expense of others and the need for any research/development in the area to be industry led. Irrespective of their views on funding of relevant research activities, all respondents identified a number of future applications of additive manufacturing as listed in Table 2 below.

Table 2. Respondent perspectives on future applications of additive manufacturing

\begin{tabular}{ll}
\hline Industry & Future applications \\
\hline Healthcare & Low volume manufacturing/prototyping; full and partial dentures, \\
& splints, surgical guides, orthodontics; rapid prototyping; custom \\
& components specific to patent, e.g., based on biometric detail \\
Automotive & Low volume spares and tooling; new product testing and trialing; \\
& spare parts; rapid production of replacement parts for repair shops as \\
& well as rapid prototype \\
Aerospace & Complex parts at low volumes; production parts that only have \\
& material when required, in shapes that can only be produced by this \\
& method of manufacturing \\
Consumer durables & Custom components specific to a consumer e.g. based on
\end{tabular}


environment, user etc.; possibility of "making your own parts" by using printing machines and files thus reducing inventory and freight costs

Specialist consumer Ability to make unique design apparel without tooling costs; products (e.g., jewellery; many applications some of which are already here: apparel)

Tools for assembly Ease of manufacture of tooling without setup costs of traditional purposes mobile phone cases; shoes and glasses etc

Other Consumer customized products; applications in every industry not just manufacturing

\section{Discussions}

This paper presents the outcomes of a preliminary analysis of data from an exploratory survey on current practices and potential future development in the additive manufacturing sector from the perspective of users of the technology in the Australasian region. The findings suggest that users recognize the benefits of additive manufacturing as well as the developments required in future in order for the technology to continue adding value to their businesses. Adoption of the technology appears to bring with staffing, training and other resource needs but it has the potential to change the way companies grow and interact with their customers and suppliers. All respondents in this study seemed to recognize that the technology is here to stay despite its current shortcomings and believed there would be a range of potential applications.

A recent article in The Guardian describes the developments in metal 3D printing as furthering a second industrial revolution [9]. These developments include the availability and decreasing costs of metal 3D printers for home use, 3D printers that can build themselves, current research on 3D printers that can produce nutritious food for astronauts, affordable 3D scanning and 3D printing as a service. The fact that many $3 \mathrm{D}$ printing patents will soon expire is also expected to create opportunities for greater innovation [10].

The potential of the technology to revolutionize manufacturing has been recognized by governments, the private sector and university researchers. As noted by the respondents in this study, the technology is still being used largely for prototyping purposes. Overcoming the limitations of the technology in order for it to be used for high-volume manufacturing remains a challenge for all interested stakeholders. Addressing the challenge will require collaboration across different sectors. In 2012, America Makes was established in the US as a network of around 100 academic institutions, companies, government agencies and non-profit organizations in order to make the country's additive manufacturing industry globally competitive. [11] In the UK, three companies, Renishaw, Hieta and Sysemia, are collaborating to address the mass-production related limitations [12]. The project is funded by the Technology Strategy Board, the UK government's innovation agency. 
As the technology becomes more scalable, small businesses that are adopting the technology in Australia will be able to experience significant market growth. Ondemand manufacturing may also become more common. Companies such as Sculpteo [13] and Shapeways [14], for instance, are already at the forefront of creating online marketplaces around 3D printing. The range of business impacts of the developments in additive manufacturing will become clearer over the next few years. This paper is an initial exploration of these developments in additive manufacturing. The authors expect to conduct further research to understand the impacts of collaborative research in additive manufacturing as well as the implications of these developments for business models.

\section{References}

1. Economics Intelligence Unit: Aiming Higher, How Manufacturers are Adding Value to their Business (2010), http://www.economistinsights.com/sites/default/files/Manufacturing\%20$\%$ 20Aiming\%20higher.pdf

2. Additive Manufacturing Special Interest Group, Technology Strategy Board: Shaping Our National Competency in Additive Manufacturing (2012), https://www.innovateuk.org/documents/1524978/1866952/Shaping\%20our\%20national\%20 competency\%20in\%20additive\%20manufacturing

3. Gibson, I., Rosen, D.W., Stucker, B.: Additive Manufacturing Technologies: Rapid Prototyping to Direct Digital Manufacturing. Springer, New York (2010)

4. Anderson, E.: Additive Manufacturing in China: Threats, Opportunities and Developments (Part 1). SITC Bulletin Analysis (2013)

5. Wohlers, T.T.: Wohler Report 2013, Additive Manufacturing and 3D Printing State of the Industry, Annual Worldwide Progress Report, Wohlers Associates, Fort Collins, CO (2013)

6. Royal Academy of Engineering: Additive Manufacturing: Opportunities and Constraints. Royal Academy of Engineering, London (2013)

7. Campbell, I., Bourell, D., Gibson, I.: Additive Manufacturing: Rapid Prototyping Coming of Age. Rapid Prototyping J. 18, 255-258 (2012)

8. Polzin, C., Spath, S., Seitz, H.: Characterization and Evaluation of a PMMA-based 3D Printing Process. Rapid Prototyping J. 19, 37-43 (2013)

9. Gibbs, S.: Metal 3D Printing and Six Key Shifts in the 'Second Industrial Revolution' (2013), http://www.theguardian.com/technology/2013/dec/09/metal-3d-printing-keydevelopments-second-industrial-revolution/print

10. Hornick, J., Roland, D.: Many 3D Printing Patents are Expiring Soon: Here's a Round Up \& Overview of Them (2013), http://3dprintingindustry.com/2013/12/29/many-3d-printingpatents-expiring-soon-heres-round-overview/

11. http://americamakes.us

12. Bharadwaj, A.: Mass Production using Additive Manufacturing? Yes, Says a New Research Collaboration (2013) http://3dprintingindustry.com/2013/12/02/mass-production-usingadditive-manufacturing-yes-says-new-research-collaboration/

13. http://www.sculpteo.com/en/

14. http://www.shapeways.com/ 